\title{
The Association Between Taste Perception with Caries Experience and Body Mass Index of 12-13 Years Old Children in the 2 Sub-Districts in Medan
}

\author{
Ami Angela Harahap ${ }^{1, *}$ Elita Elisabet Sihombing ${ }^{2}$ \\ ${ }^{1}$ Department of Pediatric Dentistry, Dentistry Faculty, Universitas Sumatera Utara \\ ${ }^{2}$ Dentistry Faculty, Universitas Sumatera Utara \\ Corresponding author.Email: harahap.ami@gmail.com
}

\begin{abstract}
Caries are a major dental health problem in Indonesia, especially in school-aged children, that affect the children's dietary habits and growth. Taste perception is one of the determining factors of children choosing certain types of food that affect oral health and BMI. The research aimed to investigate the relationship between taste perception with caries experience and the Body Mass Index (BMI) of children (12-13-year-old) in the Medan Petisah and Medan Tuntungan sub-district. This study was a cross-sectional descriptive analytics study. The data was collected from the questionnaire and clinical oral examination for the caries incidence, taste perception, and measuring the children's weights and heights to determine their BMI on 152 children. The bitter taste perception showed significant association with caries $(p=0,003)$ and the sweet taste perception with caries $(p=0,001)$. No significant was found between taste perception and BMI. Supertasters tend to be more sensitive to taste threshold levels, and caries status was in a low category.
\end{abstract}

Keywords: Caries, Taste Perception, BMI

\section{INTRODUCTION}

Dental caries is one of the most prevalent oral and dental illnesses worldwide. ${ }^{1}$ Caries in children affect eating habits, development, and academic attention. According to the World Health Organization (WHO), 60 percent to 90 percent of schoolchildren globally have caries, most prevalent in Asia and Latin America, and 25.9 percent have mouth caries. The Body Mass Index is one element to contributes caries (BMI) ${ }^{2}$.
Oral health affects dietary choices, which in turn has an impact on body weight. ${ }^{3}$ Economic, social, cultural, and behavioral factors influence food selection. ${ }^{4}$ Taste is one of the five human senses. Choosing safe and delectable food needs chemosensory work skills, including the senses of smell and taste, as well as somatosensory abilities, 
precisely surface texture, nociception, and discomfort. $^{5}$

If an unhealthy diet is maintained, it can harm health, particularly oral health. Dental caries-related poor oral health can have a long-term effect on children's nutritional status.

\section{METHODS}

The type of research conducted is descriptiveanalytic research with a cross-sectional design using questionnaires and examination sheets. The research subjects were 152 children aged 12-13 years in the Districts of Medan Petisah and Medan Tuntungan in 2019.

The sampling technique used was purposive sampling.The inclusion criteria in this study were children who had obtained permission from their parents/guardians, ASA I, did not consume drugs, did not use mouthwash at least 2 hours before.

Bitter perception examination using a 6-nPropylthiouracil (PROP) sheet was placed on the dorsal tongue (2/3 anterior of the tongue) for 30 seconds. When the subject feels the most bitter intensity, the subject assesses on a facial 7-point hedonic scale.

Measure sweetness using various sucrose concentrations ranging from $5 \%, 10 \%, 20 \%$, and $40 \%$. BMI is the result of a calculation between weight (in kilograms) and height squared (in meters) according to the sex and age of the child. According to Klein, the caries criteria were divided into caries-free, low caries, and very high caries. ${ }^{6}$

\section{DATA ANALYSIS}

The analysis used in this research is the univariate analysis and bivariate analysis.
Table 1. Frequency Distribution by Age and Gender in Medan Petisah and Medan Tuntungan Districts

\begin{tabular}{|l|c|c|}
\hline \multicolumn{1}{|c|}{ Karateristik } & $\mathrm{n}$ & $\%$ \\
\hline Ages & 86 & 56,6 \\
$\quad$ 12 years & 66 & 43,4 \\
13 years & 62 & 40,8 \\
\hline Sex & 90 & 59,2 \\
$\quad$ Male & 72 & 47,4 \\
Female & 80 & 52,6 \\
\hline Sub-district & & \\
Medan Petisah & 152 & 100 \\
Medan & & \\
Tuntungan & & \\
\hline Total & & \\
\end{tabular}

The data in Table 1 shows the distribution of subjects based on age obtained by 86 children aged 12 years $(56.6 \%)$ and 66 children aged 13 years $(43.4 \%)$, the distribution of subjects based on gender received data for male 62 children $(40,8 \%)$ and women as many as 90 children (59.2\%). In contrast, the distribution of subjects based on sub-districts originating from Medan Petisah District was 72 children (47.4\%) and Medan Tuntungan District as many as 80 people $(52.6 \%)$.

Table 2. Relationship between Bitter Taste Perception and Caries Experience

\begin{tabular}{|c|c|c|c|}
\hline $\begin{array}{c}\text { Bitter } \\
\text { Category } \\
(\mathrm{n}=152)\end{array}$ & $\mathrm{n}$ & $\begin{array}{c}\text { DMFT } \\
\text { Mean }\end{array}$ & $p$ \\
\hline Super taster & 47 & $1,51 \pm 1,89$ & \multirow{2}{*}{0,003} \\
\cline { 1 - 3 } $\begin{array}{c}\text { Medium } \\
\text { taster }\end{array}$ & 76 & $2,50 \pm 2,78$ & \\
\hline Non taster & 29 & $3,31 \pm 2,66$ & \\
\hline$p<0,05$ & & &
\end{tabular}

Table 2 shows that when viewed based on the caries index, the supertaster category is at an average low caries index $(1.51 \pm 1.89)$, the same as the medium taster $(2.50 \pm 2.78)$, while the nontaster is on moderate caries index $(3.31 \pm 2.66)$ 
Table 3. Relationship of Bitter Taste Category with Caries Index

\begin{tabular}{|c|c|c|c|c|c|c|c|c|}
\hline \multirow{2}{*}{$\begin{array}{c}\text { Bitter } \\
\text { Category }\end{array}$} & \multicolumn{6}{|c|}{ Caries Index } & \multirow{2}{*}{$\mathrm{n}$} & \multirow{2}{*}{$p$} \\
\hline & $\begin{array}{c}\text { Caries } \\
\text { free } \\
\mathrm{n}(\%)\end{array}$ & $\begin{array}{c}\text { Very low } \\
\mathrm{n}(\%)\end{array}$ & $\begin{array}{l}\text { Low } \\
\mathrm{n}(\%)\end{array}$ & $\begin{array}{c}\text { Medium } \\
\mathrm{n}(\%)\end{array}$ & $\begin{array}{l}\text { Hight } \\
\mathrm{n}(\%)\end{array}$ & $\begin{array}{c}\text { Very } \\
\text { Hight } \\
\mathrm{n}(\%)\end{array}$ & & \\
\hline Super taster & $19(40,4)$ & $11(23,4)$ & $7(14,9)$ & $6(12,8)$ & $2(4,3)$ & $2(4,3)$ & 47 & \multirow{4}{*}{0,003} \\
\hline Medium & $23(30,3)$ & $11(14,5)$ & $10(13,2)$ & $17(22,4)$ & $11(14,5)$ & $4(5,3)$ & 76 & \\
\hline Non taster & $2(6,9)$ & $5(17,2)$ & $8(27,6)$ & $7(24,1)$ & $3(10,3)$ & $4(13,8)$ & 29 & \\
\hline Total & $44(28,9)$ & $27(17,8)$ & $25(16,4)$ & $30(19,7)$ & $16(10,5)$ & $10(6,6)$ & 152 & \\
\hline
\end{tabular}

$p<0,05$

According to Table 3, the Kruskal-Wallis statistical test yielded a p-value of 0.0030 .05 . There was a significant relationship between bitter taste perception and the caries index. The supertaster category included 19 children with a caries-free index (40.4 percent), 11 children with a shallow index (23.4 percent), seven children with a low index (14.9 percent), and two children with a high and very high index (4.3 percent ).

The caries-free index was assigned to 23 children in the medium taster category (30.3 percent), medium 14 children (20 percent), low and high 11 children (14.5 percent), low ten children (13.2 percent), and very high four children (5.3 percent ). The nontaster category included eight children with a moderate caries index (27.6\%), seven children $(24.1 \%)$, very low five children $(17.2 \%)$, very high four children (13.8\%), and high three children (10.3 percent ). In comparison, two children were caries-free (6.9 percent ).

Table 4. The Relationship between Perception of Sweetness and Experience of Caries

\begin{tabular}{|c|c|c|c|}
\hline $\begin{array}{c}\text { Bitter Category } \\
(\mathrm{n}=152)\end{array}$ & $\mathrm{n}$ & $\begin{array}{c}\text { DMFT } \\
\text { Mean }\end{array}$ & $p$ \\
\hline Super taster & 31 & $1,13 \pm 1,45$ & \multirow{2}{*}{0,001} \\
\cline { 1 - 3 } Medium taster & 70 & $3,06 \pm 2,85$ & \\
\hline Non taster & 51 & $2,12 \pm 2,43$ & \\
\hline$p<0,05$
\end{tabular}

Table 4 shows that when viewed based on the caries index, the supertaster category is at an average very low caries index $(1.13 \pm 1.45)$, medium taster has a moderate caries index $(3.06 \pm 2.85)$, while taster was at low caries index $(2.12 \pm 2.43)$.

Table 5 shows that the Kruskal-Wallis statistical test yielded a p-value of 0.0010 .05 , indicating a significant difference between the perception of sweetness and the caries index. There are 15 children in the supertaster category (48.4 percent) who are caries-free, six children in the very low and low category (19.4 percent), three children in the moderate category (9.7 percent), and one child in the high category (48.4 percent) (3.2 percent ). There are no children in the supertaster category who have a high caries index.

Table 6 depicts the distribution of bitter taste perception in the supertaster category in normal BMI children as many as 31 (66.0 percent), obese children as many as 10 (21.3 percent), and obese children as many as 6. (12.8 percent ). In the normal BMI category, 49 children (64.8 percent) were in the medium taster category, 15 children (20.5 percent) were obese, and 12 children were obese (14.8 percent ). The non-tasting category for normal BMI included 19 children (64.7 percent), eight obese children (29.4 percent), and two obese children (5.9 percent ). The relationship between bitter taste perception and a value $(p=0.757)$ was not discovered. 
Table 5. Relationship between Sweet Taste Category and Caries Index

\begin{tabular}{|c|c|c|c|c|c|c|c|c|}
\hline \multirow{2}{*}{$\begin{array}{l}\text { Bitter Category } \\
\quad(\mathrm{n}=152)\end{array}$} & \multicolumn{6}{|c|}{ Caries Index } & \multirow{2}{*}{$\mathrm{n}$} & \multirow{2}{*}{$p^{*}$} \\
\hline & $\begin{array}{c}\text { Caries } \\
\text { free } \\
\mathrm{n}(\%)\end{array}$ & $\begin{array}{c}\text { Very low } \\
\mathrm{n}(\%)\end{array}$ & $\begin{array}{l}\text { Low } \\
\mathrm{n}(\%)\end{array}$ & $\begin{array}{c}\text { Medium } \\
\mathrm{n}(\%)\end{array}$ & $\begin{array}{l}\text { Hight } \\
\mathrm{n}(\%)\end{array}$ & $\begin{array}{c}\text { Very } \\
\text { Hight } \\
\text { n(\%) }\end{array}$ & & \\
\hline Super taster & $15(48,4)$ & $6(19,4)$ & $6(19,4)$ & $3(9,7)$ & $1(3,2)$ & $0(0)$ & 31 & \\
\hline Medium & $14(20,0)$ & $10(14,3)$ & $11(15,7)$ & $17(24,3)$ & $11(15,7)$ & $7(10)$ & 70 & 0,001 \\
\hline Non taster & $15(29,4)$ & $11(21,6)$ & $8(15,7)$ & $10(19,6)$ & $4(7,8)$ & $3(5,9)$ & 51 & \\
\hline Total & $44(28,9)$ & $27(17,8)$ & $25(16,4)$ & $30(19,7)$ & $16(10,5)$ & $10(6,6)$ & 152 & \\
\hline
\end{tabular}
$p<0,05$

Table 6. Relationship between Bitter Taste Perception and BMI

\begin{tabular}{|c|c|c|c|c|c|}
\hline \multirow{2}{*}{ Bitter Category } & \multicolumn{3}{|c|}{ BMI category } & \multirow{2}{*}{ Total } & $p$ \\
\cline { 2 - 5 } & $\begin{array}{c}\text { Normal } \\
\mathrm{n}(\%)\end{array}$ & $\begin{array}{c}\text { Fatty } \\
\mathrm{n}(\%)\end{array}$ & $\begin{array}{c}\text { Obesity } \\
\mathrm{n}(\%)\end{array}$ & & \multirow{2}{*}{0,757} \\
\hline Super taster & $31(66,0)$ & $49(64,5)$ & $19(65,5)$ & 33 & 20 \\
\hline Medium & $10(21,3)$ & $15(19,7)$ & $8(27,6)$ & $2(6,9)$ & 20 \\
\hline Non taster & $6(12,8)$ & $12(15,8)$ & & \\
\hline
\end{tabular}

Table 7. Relationship of Sweet Taste Perception with BMI

\begin{tabular}{|c|c|c|c|c|c|}
\hline \multirow{2}{*}{ Bitter Category } & \multicolumn{3}{|c|}{ BMI category } & \multirow{2}{*}{ Total } & $p$ \\
\cline { 2 - 5 } & $\begin{array}{c}\text { Normal } \\
\mathrm{n}(\%)\end{array}$ & $\begin{array}{c}\text { Fatty } \\
\mathrm{n}(\%)\end{array}$ & $\begin{array}{c}\text { Obesity } \\
\mathrm{n}(\%)\end{array}$ & 99 & \multirow{2}{*}{0,131} \\
\hline Super taster & $18(58,1)$ & $52(74,3)$ & $29(56,9)$ & 33 & \\
\hline Medium & $10(32,3)$ & $9(12,9)$ & $14(27,5)$ & $8(15,7)$ & 20 \\
\hline Non taster & $3(9,7)$ & $9(12,9)$ & & \\
\hline
\end{tabular}

$$
p>0,05
$$

According to Table 7, the distribution of sweet taste in the supertaster category in normal BMI is as many as 18 children (58.1 percent), ten children fat (32.3 percent), and three children obese (9.7 percent ). In the normal BMI category, 52 children (74.3 percent) were in the medium taster category, while nine children (12.9 percent) were obese (12.9 percent ). The non-tasting category of normal BMI included 29 children $(56.9 \%), 14$ children fat $(27.5 \%)$, and eight children obese (15.7 percent ). A relationship between the perception of sweetness and a value of ( $p$ $=0.131)$ was not discovered.

\section{DISCUSSION}

The information gathered from the research findings on the distribution of taste perception is seen from caries and BMI. It was discovered that assessing bitter taste perception using the PROP material validated in Karmakar's research can only be used to determine bitter taste perception, not the threshold. ${ }^{7}$ The Linkert Scale divides bitter taste perception into five categories: very bitter, bitter, doubtful, ordinary, course, and no taste, divided into three categories: supertaster, medium taster, and nontaster. The child in the supertaster category thought PROP was very bitter 
because it made him feel nauseous. According to the child's response in the medium taster category, PROP was bitter and ordinary because it tasted like taking medicine. The child's response in the nontaster category, on the other hand, felt that PROP did not taste because the child was hesitant or couldn't detect the taste of the PROP. According to the findings of this study, the majority of children are medium tasters. According to Rupes and Nayak in India, the results of this study are nearly identical to the research that found that supertasters accounted for roughly onethird of the sample population and medium tasters accounted for nearly half of the sample population. ${ }^{8}$

Sweetness perception was evaluated using Whatman paper with a $2 \times 2 \mathrm{~cm}$ surface area and concentrations of $0.625,1.25,2.5,5,10,20$, and $40 \%$. The concentrations were divided into three categories: supertaster ( 0.625 percent and 1.25 percent $)$, medium taster ( 2.5 percent and 5 percent), and nontaster (10 percent - 40 percent). The child did not feel the concentration of 0.625 percent. As a result, the taste perception threshold is 1.25 percent because the child can feel the sweet taste threshold at that concentration. With 70 children (46.1 percent), the sweet category of medium taster is the most common, followed by the nontaster category with 51 children (33.6 percent) and the supertaster category with 31 children (20.4 percent ). According to Borazon et al., in the Philippines, the medium taster category has the most significant number of children $(\mathrm{n}=71) .^{9}$

Klein's criteria were used to assess the caries experience. According to Klein's caries experience evaluation, decayed was indicated for all cariesexperienced teeth, presence of secondary caries in permanent fillings, teeth with temporary fillings, deep cavities with possible pulp involvement, then missing was suggested for the existence of tooth loss caused by caries, and fillers were indicated for teeth that were affected. Dental caries necessitated the use of fillings. The caries index in this study is the same as that of Subendi et al. in children aged 12-13 years in the Lalitpur and Kritipur region of Nepal, but their study had a lower mean caries value of (1.6 0.14), which was classified as low. ${ }^{10}$

BMI is calculated by dividing weight (kilograms) by height (meters), which is then compared to the Body Mass Index or BMI table according to RISKESDAS 2013 based on the child's gender and age. Vanda $\mathrm{M}$ et al. research's BMI was divided into four categories and assessed using the 2013 RISKESDAS BMI table so that the BMI categories studied were thin (BMI -2 SD), normal (BMI -2 to $1 \mathrm{SD}$ ), and obese (BMI $1-2 \mathrm{SD}$ ). And then there's obesity (BMI 2 SD). The study's findings revealed a mean BMI of $21.535 .06 \mathrm{~kg}$. The minimum and maximum weights are $15.13 \mathrm{~kg}$ and $34.97 \mathrm{~kg}$, respectively. According to Ashi et al., the results of the study in three countries, namely Italy, Mexico, and Saudi Arabia, showed the same results as this study, that the highest BMI category was normal. ${ }^{11}$

The findings of this study suggest a link between the perception of bitter taste and the experience of caries. The Kruskal-Wallis statistical test yielded a pvalue of 0.003 , indicating a significant relationship between the bitter category and caries experience. The results revealed that the supertaster category had a lower caries index $\left(\begin{array}{lll}1.51 & 1.89\end{array}\right)$ than the medium taster category (2.50 2.78), and the nontaster category had a higher caries index $(3,31$ 2.66). Firmim et al. research .'s in Brazil discovered that children living in rural and urban areas had different bitter sensitivity relationships to caries. There is a significant relationship $(\mathrm{p}=0.005)$ between the perception of bitterness and caries in urban areas but not in rural areas $(p=0.180) .{ }^{12}$ This study also discovered a link between the perception of sweetness and the 
experience of caries. The Kruskal-Wallis statistical test yielded a p-value of 0.001 , indicating a significant relationship between the sweet category and caries experience. According to the findings, the supertaster category has a low caries index average (1.13 1.45). It differs from the moderate caries index's medium taster category (3.06 2.85) and the low caries index's nontaster category (2.12 2.43). Similarly, Ahmed et al. research .'s in Baghdad, Iraq, found a significant relationship between sugar intake and caries experience with a value $(\mathrm{p}=0.001)$. After five years of low sugar availability in the country, DMFT in 12year-old schoolchildren was significantly reduced. ${ }^{13}$

Research has shown no correlation between bitter taste perception and BMI ( $\mathrm{p}=0.757)$. According to the findings of this study, children with bitter taste perception in the supertaster category have a BMI of standard 31 (66.0 percent), fat BMI of 10 (21.3 percent), and obese BMI of 6 (12.8 percent). Borazon, Campos, and Pinto's research show the same thing: there is no statistically significant relationship. ${ }^{14,15}$ According to the findings of this study, there is no relationship between perception of sweetness and BMI.

The Chi-Square statistical test yielded a p-value of 0.131 , indicating no significant difference between the sweet category and the BMI. Table 7 shows that children with a sweet taste in the supertaster category were found primarily in the BMI category, namely normal 18 (58.1 percent), followed by fat BMI 10 (32.3 percent), and obese BMI 3 (32.3 percent) (9.7 percent ). Similarly, Ashi et al. found no significant relationship between BMI and sweetness threshold or sweet preference and dental caries in two studies conducted in Sweden, Saudi Arabia, and Italy. ${ }^{12}$

\section{CONCLUSION}

According to the findings of this study, children who are supertasters of bitter taste have lower caries than nontasters. Children who perceive the sweetness of supertasters, on the other hand, have lower caries. As a result, it can persuade parents to provide a low-sugar diet and healthy foods like vegetables. More research with a more evenly distributed number of subjects in each category and diet books is required to determine the relationship between the perception of sweetness and bitter taste and caries and BMI.

\section{REFERENCES}

[1] Dixit LP, Shakya A, Shrestha M, Shrestha A. Dental caries prevalence,oral health knowledge and practice among indegenous Chepang school children of Nepal. BMC Oral Health 2013; 13 (20): 1-5.

[2] Guo E, Ma N, Yang F, Yu J, Yuan X, Zhang Y, et al. Caries experience and its association with weight status among 8-year-old children in Qingdao, China. J Int Soc Prev Community Dent 2015; 5 (1): 52-8.

[3] Roth RA. Diet and weight control. In: Garza D. Nutrition and diet therapy, $10^{\text {th }}$ ed., New York: Cengage Learning., 2011: 295-301.

[4] Markam V, Banda NR, Singh G, Chakravarthy K, Gupta M. Does taste perception effect Body Mass Index in preschool children? J Clin Diagn Res 2015; 9 (12): 1-4.

[5] Sunariani J. Indera rasa pengecapan di dalam rongga mulut., Sidoarjo: Dwiputra Pustaka Jaya, 2014: 1-50.

[6] Ashi H, Campus G, Forslund HB. The influence of sweet taste perception on dietary intake in relation to dental caries and bmi in Saudi Arabian schoolchlidren. Int J Dent 2017: 1-8.

[7] Karmakar P, Arora R, Patel C, Sarvaiya B, Singh A, Patel M. Caries risk in children of Undaipur city, India using genetic taste sensitivity to 6-npropylthiouracil. J Int Soc Prev 2016; 6(6): 5238.

[8] Rupesh S dan Nayak U. Genetic sensitivity to the bitter taste of 6-n propylthioracil: A new risk determinant for dental caries in children. J Indian Soc pedod Prev Dent 2006; 63-8. 
[9] Lin BP. Caries experience in children with various genetic sensitivity levels to the bitter taste of 6-n-propylthiouracil (PROP): a pilot study. Ped Dent 2003; 25(1): 37-41.

[10] Subendi B, Shakya P, KC U, Jnawali M, Paudyal BD, Acharya A et al. Prevalence of dental caries in 5-6 years and 12-13 years age group of school children of Kathmandu valley. J Nepal Med Assoc 2011; 51(184): 176-81.

[11] Kemenkes RI. Riset kesahatan dasar tahun 2013. Jakarta: Kemenkes RI 2013; 209-20.

[12] Ashi H, Campus G, Klingberg G, Forslund HB, Lingstrom P. Childhood obesity in relation to sweet taste perception and dental caries - a cross-sectional multicenter study. Food and Nut Res 2019; 63: 1-7.

[13] Firquim TR, Frederico RC, Maciel SM, Junior AG, Walter LR. Senstivity to bitter and sweet taste perception in schoolchildren and their relation to dental caries. Oral Healt Prev Dent 2010; 8: 253-9.

[14] Ahmed N, Astrom A, Bergeb NS. Dental caries prevalence and risk factors among 12year old schoolchildren in Baghdad, Iraq: a post-war survey. Int Dent J 2007; 57: 36-44.

[15] Borazon EQ, Villarino BJ, Magbuhat RM, Sabandal ML. Relationship of PROP (6-npropylthiouracil) taster status with Body Mass Index, food preference, and consumtion of filipino adolescents. Food Res Int 2012; 47: 229-35.

[16] Campos MC dan Pinto ME. 6-npropylthiouracil (PROP) taster status in Brazilian adults. Campinas 2012; 32(4): 6738. 